\title{
3D Numerical Simulation of Hair Formation Process Using a Particle Model
}

\author{
Katsuya Nagayama', Shogo Matsuoka ${ }^{1}$, Naoko Morisaki², Hiroyuki Taguchi' ${ }^{2}$ \\ ${ }^{1}$ Kyushu Institute of Technology, Fukuoka, Japan \\ ${ }^{2}$ Kao Corporation, Tochigi, Japan \\ Email: nagayama@mse.kyutech.ac.jp
}

Received 3 January 2015; accepted 3 February 2015; published 6 February 2015

Copyright (C) 2015 by authors and Scientific Research Publishing Inc.

This work is licensed under the Creative Commons Attribution International License (CC BY).

http://creativecommons.org/licenses/by/4.0/

(c) (i) Open Access

\begin{abstract}
Hair is very important in determining human appearance. Although there are numerous observed data and experimental recordings for hair, a detailed mechanism of hair formation has not yet been elucidated. Therefore, in this study, a simulation of the method of formative process of hair roots was done using a 3D particle model. The model contains details of the cell growth from the hair matrix cells and changes from spherical to non-spherical oval shape. Simulation results were able to exhibit the hair formation process from the base of the hair follicle. Furthermore, at the surface opening of the follicle, the hair structure was recorded. Therefore, this model can be used to clarify the mechanism of hair root formation.
\end{abstract}

\section{Keywords}

Numerical Simulation, Hair Formation, Particle Model

\section{Introduction}

In recent years, there has been an increasing concern in the cosmetics industry, and research on anti-aging of skin and hair has been rapidly developing. In particular, hair is now considered as a very important factor in determining human appearance, which increases the need of clarifying hair root formation mechanisms.

This study developed a method for analysis of the formation of hair root using a particle model. Numerical simulations of hair formation process, such as cell division, transformation of cell, and keratinization, were carried out based on this 3D non-spherical model. Our aims are to clarify the mechanism of hair formation and to contribute to the field of hair beautification. We used numerical simulations to understand and clarify this phenomenon. We believe that the model will be applicable to the diagnostic system of hair beauty. 


\section{Analysis Object and Model Description}

\subsection{Analysis 0bject}

Figure 1 shows the image of a hair root as the analysis object, and the roles of each cell type are described [1]-[4]. The hair root is surrounded by the inner root sheath. Basically, there are three zones: cells divide at the bottom, cells transform and change their properties at the middle, and finally, elastic solid structures are fixed. The dermal papilla is at the bottom center of the follicle. Hair matrix cells which are present adjacent to the dermal papilla divide actively. The cells proximal to the critical line change their shape and properties. The hair matrix cells present under the critical line divide actively. The cells change to cortex and cuticle cells after growing beyond the critical line and transform from a spherical to a spherical-elliptical shape. When the cells become cured and exceed the keratogenous zone, the cells are filled with insoluble keratin protein. At this point, the cells retain their structure as elastic solid, and hair strand is considered to have matured as it emerges above the skin.

\subsection{Model Description}

The particle model is introduced to simulate the hair formation process [5] [6]. The model considers the interaction among particles and pursues motions of particles in a Lagrangian way. This method is suitable for analysis either when each particle shape deforms largely or when the number of calculation points is constantly moving. The cellular particles move in response to the influence of inter-particle forces: volume conservation force and spring force. The volume conservation force $F$ in Equation (1) works to keep the particles apart. Due to the repulsive forces, the particles eventually move to a stable distance. Here $k$ is the coefficient, $d d r$ is the distance between two particles, $d r 0$ is the standard distance (12.4 $\mu \mathrm{m}$ in this case), $a$ and $r$ are the conversion factors for the movement of the non-spherical particles, $a$ is the particle size of the target, and $r$ is the reference particle diameter. The spring force $f$ in Equation (2) works to make the continuum of the cellular particles structural. Here, $k^{\prime}$ is the coefficient of elastic spring. As the hairs grow, particles are increasingly connected with the surrounding particles, the spring force between the particles becomes strong, and the particles become solid and develop elasticity. In Equation (3), this is the sum of the forces exerted by surrounding particles, where particles are gradually moved to a position of the force balance. $x$ and $x^{\prime}$ are the positions before and after movement due to these forces. $\alpha$ and $\beta$ are coefficients and the values are 1 and $1 / 300$, respectively.

$$
\begin{gathered}
\vec{F}=\{k \cdot(d d r-d r 0) \cdot(a / r)\} \frac{d d \vec{r}}{d d r} \\
\vec{f}=-k^{\prime} \cdot\left(1-\frac{d d r}{d r 0}\right) \cdot\left[1-\left(1-\frac{d d r}{d r 0}\right)^{4}\right] \cdot \frac{d d \vec{r}}{d r 0} \\
\vec{x}^{\prime}=\vec{x}+\left(\alpha \cdot \sum \vec{F}+\beta \cdot \sum \vec{f}\right)
\end{gathered}
$$

Figure 2 shows a flow chart of analysis steps in the present study. First, cells for the initial shape are placed. The cells are split from matrix cells and increase. Inter-particle force in Equation (1) and spring force in Equation (2)

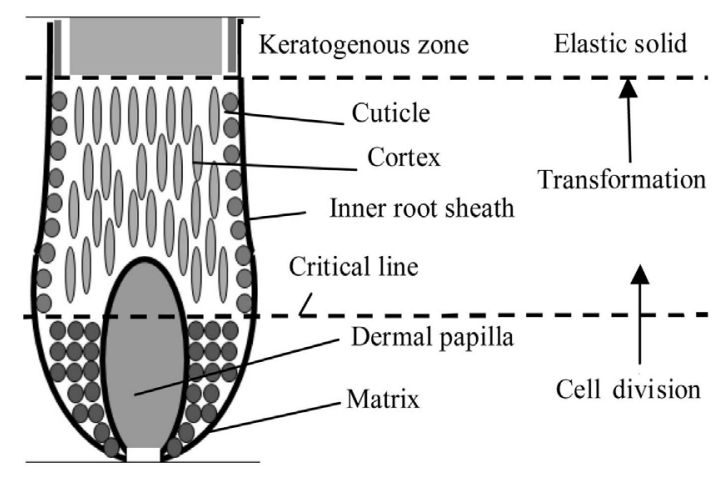

Figure 1. Image of hair root as analysis object. 


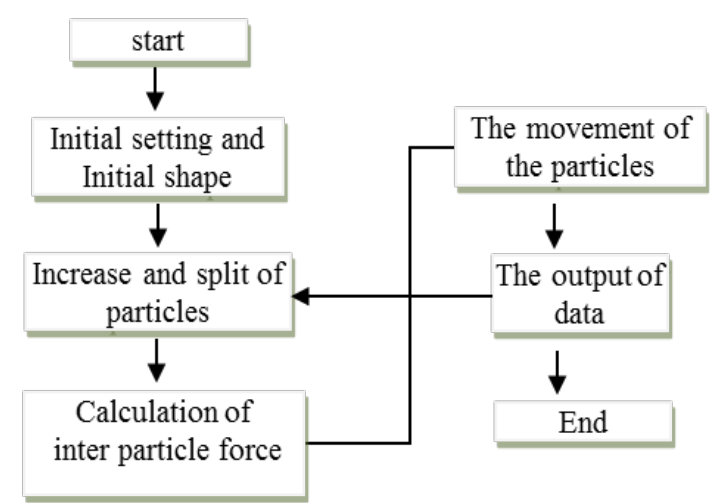

Figure 2. Analysis flowchart.

are calculated. Following this, the cells are moved upward using Equation (3), changing their shape and physical properties. Calculations are continued, and finally, calculation results are output.

\section{Calculation Conditions}

An initial arrangement of the 3D model is shown in Figure 3 and consists of matrix cells, dermal papilla, and the inner root sheath. The initial cell particle has a spherical shape with $12.4 \mu \mathrm{m}$ diameters, and it changes to cortex gradually after the critical line and changes shape gradually to become non-spherical particles of $3.9 \mu \mathrm{m}$ diameter and $124 \mu \mathrm{m}$ height. From the matrix cell to the cortex, the shape change occurs in one day. The birth of new hair matrix cells occurs once in a half a day. Indeed, cell division after hair formation is assumed to occur 10 times per day. Cell migration after division is free to move under volume conservation force. Because of changing to cortex cells, a spring force is generated between the particles (gradually between each neighboring cell), and the shape of the elastic hair is determined. The cuticle comprises multiple thin layers covering the cortex and presenting its model in a figure is difficult. Therefore, we have simplified the cuticle model so that outside surface particles are connected to the elasticity of the cuticle cells.

\section{Results and Discussion}

Figure 4 shows a cross-section of the simulation for results of hair metabolism. Figure 4(d) and Figure 4(a) show the result with and without, considering the cuticle and elastic force after three days, respectively. Figure 4(a) is the result without considering spring force in the spherical model. Particles can move under volume conservation force; hair is unstructured and cannot keep its shape. Figure 4(b), Figure 4(c), and Figure 4(d) show the results of a non-spherical shape with spring force after one day, two day, and three days, respectively. As shown in Figure 4(b), after one day, spring force emerges between cells over the critical line, and solidification occurs inside the inner sheath. As shown in Figure 4(c), after two days, hair maintains the solid structure because spring force emerges and reaches the exit of the inner sheath. The hair shape is maintained even after three days, as shown in Figure 4(d).

A closer look at the results of the consideration of the elastic force, non-spherical perturbation begins after the first day in Figure 4(b). Cells reach the outlet and are fixed after two days, as can be seen in Figure 4(c). Finally, after 3 days (Figure 4(d)), hair emerges above skin, while retaining its shape.

Figure 5 shows the detailed results of the three-dimensional cross-section near the exit of the hair follicle. In Figure 5(a), the cells are aligned in the spherical model, which does not involve a shape change. Figure 5(b-1) and Figure 5(b-2) display the results with the non-spherical model. The particles appear to be randomly located when shown by the sphere symbol in Figure 5(b-1), whereas it can be seen that the cells are arranged densely in the non-spherical model, as shown in Figure 5(b-2). Although the simulation successfully reproduced the hair shape with rod-like cortex cells, it could not model cuticles that cover the cortex in real hair.

\section{Conclusion}

In this study, 3D particle simulations of hair formation processes at the hair root were carried out. The model 


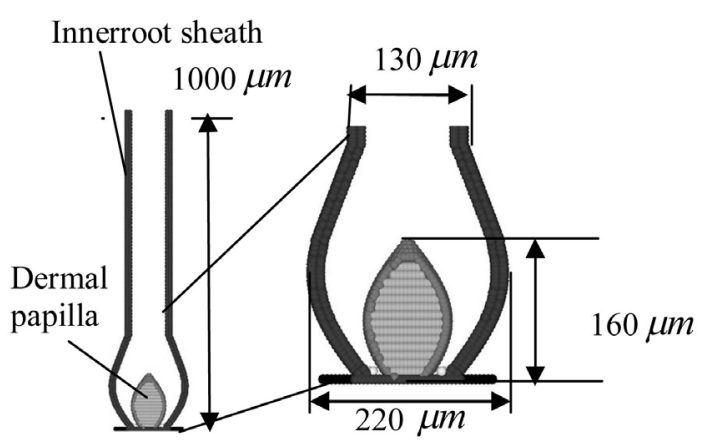

(a) Whole view (b) Enlarged view

Figure 3. Initial particle setting.

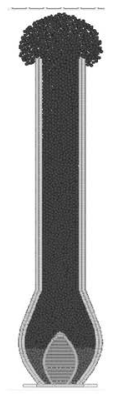

(a)Three days Spherical shape without spring force
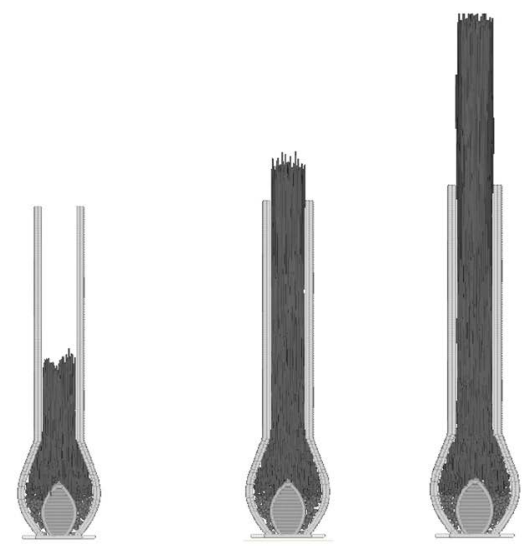

(b)One day (c)Two days (d)Three days (b), (c), (d) Non-spherical shape with spring force

Figure 4. Cross section of simulated results of the hair metabolism.

$\downarrow$ Inner sheath

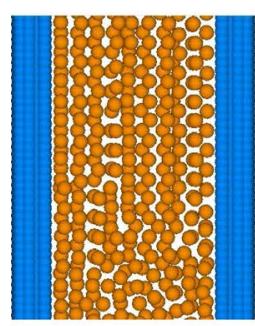

(a)Spherical model

\section{$\downarrow$ Cortex}

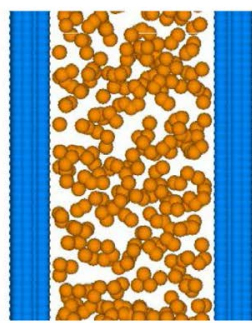

(b-1) Non-spherical model with spherical symbol $\downarrow$ Cortex

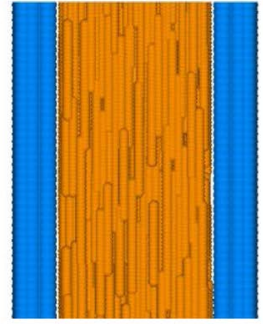

(b-2) Non-spherical model with non-spherical symbol

Figure 5. Results of detailed three dimensional structure of hair.

focuses on cell growth from the hair matrix cells and changes from spherical shape to the non-spherical elliptical shape. At the bottom of the follicle, the volume conservation force is dominant. As cells move toward the surface, spring force gradually emerges and becomes dominant at the exit site of the hair root. Simulation results, according to the model, were able to express the hair formation process from the base of the hair follicle. At the surface opening of the follicle, the hair structure could be assessed. Therefore, the model can be used as a simulation tool for hair formation processes with a change in cell shape. In future, the model will help elucidate the mechanisms of hair growth with reference to the actual phenomena, and will be expected to contribute to beauty diagnosis of hair. 


\section{References}

[1] Kobori, T. (1987) Hair Medicine. Bunko-do Co., Japan, 21-27.

[2] Ohyama, M., Terumura, A., Tock, C.L., Radonovich, M.F., Pise-Masison, C.A., Hopping, S.B., Brady, J.N., Udey, M.C. and Vogel, J.C. (2006) Characterization and Isolation of Stem Cell-Enriched Human Hair Follicle Bulge Cells. Journal of Clinical Investigation, 116, 249-260. http://dx.doi.org/10.1172/JCI26043

[3] Matsuzaki, T. (2008) Technologies for Hair Reconstruction and Their Applicability for Pharmaceutical Research. Yakugaku Zasshi, 128, 11-20. http://dx.doi.org/10.1248/yakushi.128.11

[4] Rogers, G. (2004) Hair Follicle Differentiation and Regulation. International Journal of Developmental Biology, 48, 163-179. http://dx.doi.org/10.1387/ijdb.15272381

[5] Hashiguchi, S. and Nagayama, K. (2011) Construction of a Hair Formation Analysis Method Using the Particle Model. Bioengineering Conference, 23th Japan Society of Mechanical Engineers, 9D-01, 355-356.

[6] Matsuoka, S., Nagayama, K., Taguchi, H. and Morisaki, N. (2012) Analysis of the Formation of the Hair Using a Particle Model. 2012 Biomedical Engineering Symposium Proceedings, 47-48. 
Scientific Research Publishing (SCIRP) is one of the largest Open Access journal publishers. It is currently publishing more than 200 open access, online, peer-reviewed journals covering a wide range of academic disciplines. SCIRP serves the worldwide academic communities and contributes to the progress and application of science with its publication.

Other selected journals from SCIRP are listed as below. Submit your manuscript to us via either submit@scirp.org or Online Submission Portal.
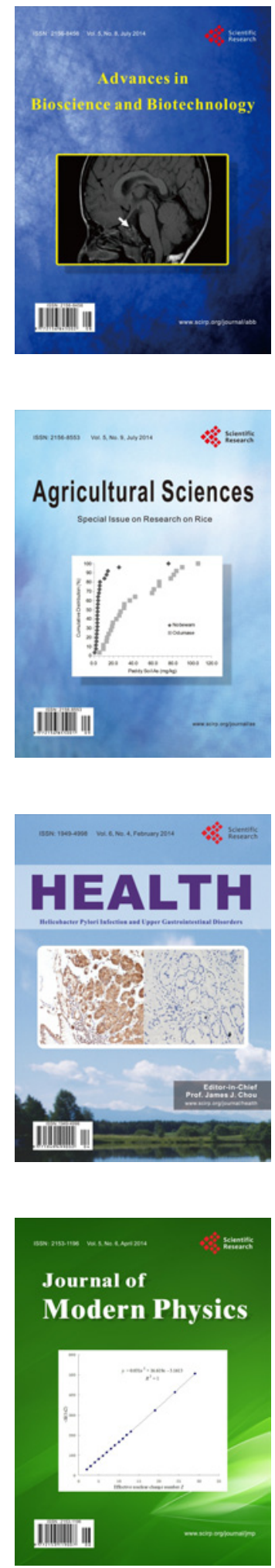
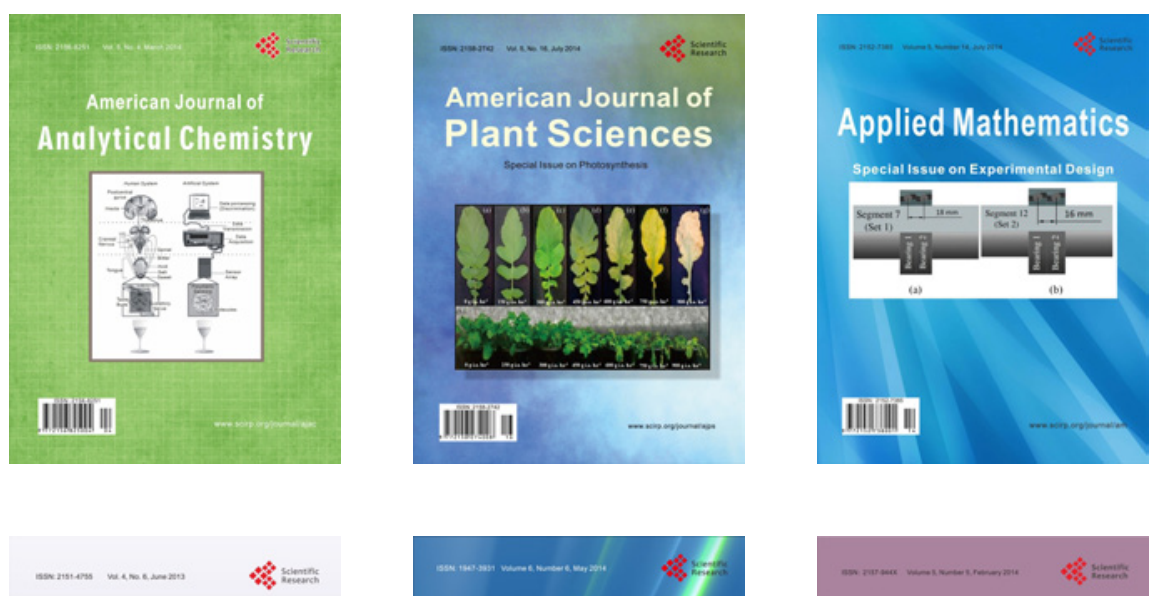

Creative Education
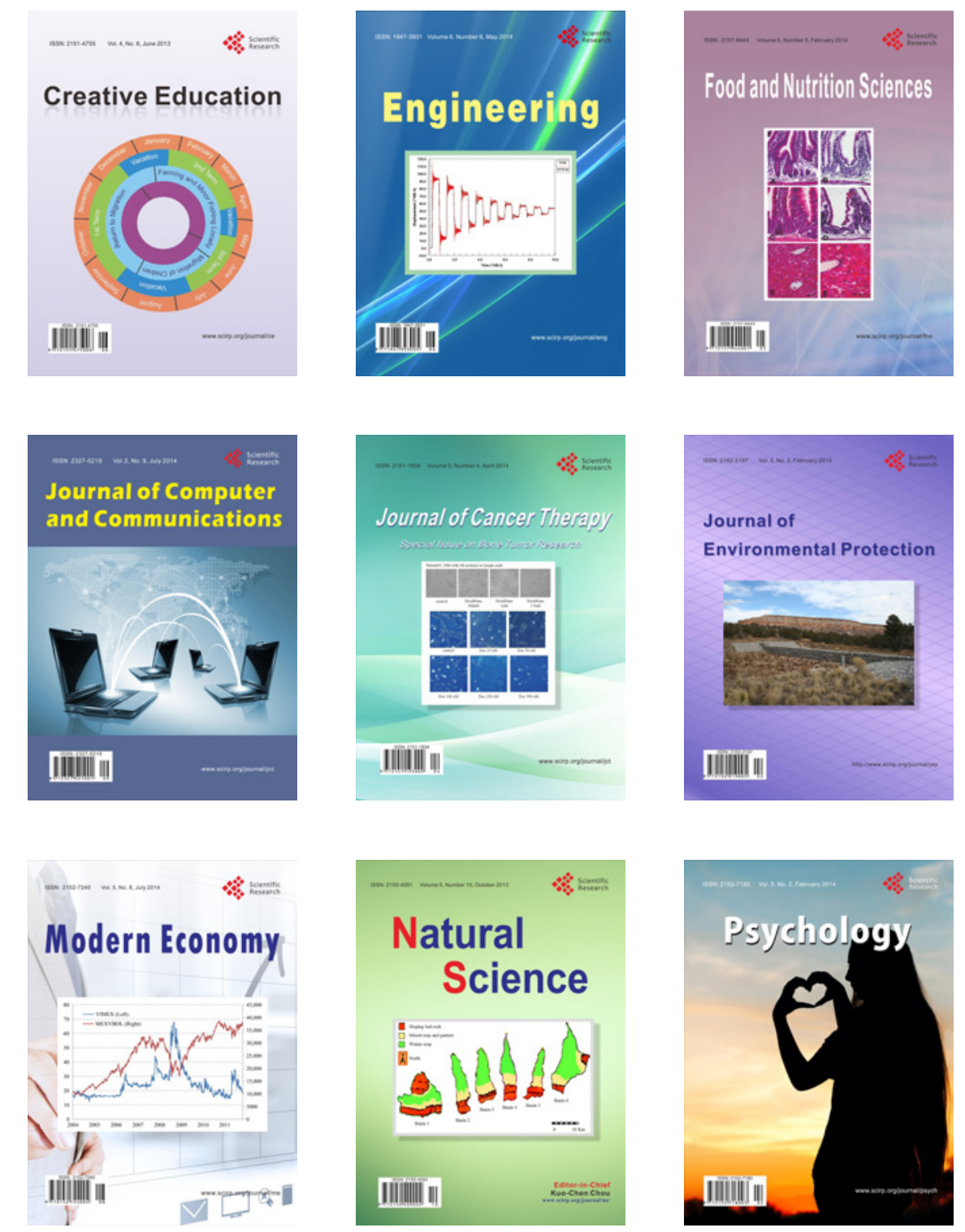